\title{
Different Spectrophotometric Methods for Simultaneous Determination of Trelagliptin and Its Acid Degradation Product
}

\author{
Shereen Mowaka $\mathbb{D}^{1,2,3}$ Bassam M. Ayoub $\mathbb{D}^{2,3}$ Mostafa A. Hassan, ${ }^{2,3,4}$ and \\ Wafaa A. Zaghary ${ }^{4}$ \\ ${ }^{1}$ Analytical Chemistry Department, Faculty of Pharmacy, Helwan University, Ein Helwan, Cairo 11795, Egypt \\ ${ }^{2}$ Pharmaceutical Chemistry Department, Faculty of Pharmacy, The British University in Egypt, El-Shorouk City, \\ Cairo 11837, Egypt \\ ${ }^{3}$ The Center for Drug Research and Development (CDRD), Faculty of Pharmacy, The British University in Egypt, El-Shorouk City, \\ Cairo 11837, Egypt \\ ${ }^{4}$ Pharmaceutical Chemistry Department, Faculty of Pharmacy, Helwan University, Ein Helwan, Cairo 11795, Egypt
}

Correspondence should be addressed to Bassam M. Ayoub; bassam.ayoub@bue.edu.eg

Received 5 July 2017; Accepted 3 December 2017; Published 30 January 2018

Academic Editor: Krishna K. Verma

Copyright $\odot 2018$ Shereen Mowaka et al. This is an open access article distributed under the Creative Commons Attribution License, which permits unrestricted use, distribution, and reproduction in any medium, provided the original work is properly cited.

New spectrophotometric and chemometric methods were carried out for the simultaneous assay of trelagliptin (TRG) and its acid degradation product (TAD) and applied successfully as a stability indicating assay to recently approved Zafatek ${ }^{\circledR}$ tablets. TAD was monitored using TLC to ensure complete degradation. Furthermore, HPLC was used to confirm dealing with one major acid degradation product. The proposed methods were developed by manipulating zero-order, first-derivative, and ratio spectra of TRG and TAD using simultaneous equation, first-derivative, and mean-centering methods, respectively. Using Spectra Manager II and Minitab v.14 software, the absorbance at $274 \mathrm{~nm}-260.4 \mathrm{~nm}$, amplitudes at $260.4 \mathrm{~nm}-274.0 \mathrm{~nm}$, and mean-centered values at $287.6 \mathrm{~nm}-257.2 \mathrm{~nm}$ were measured against methanol as a blank for TRG and TAD, respectively. Linearity and the other validation parameters were acceptable at concentration ranges of $5-50 \mu \mathrm{g} / \mathrm{mL}$ and $2.5-25 \mu \mathrm{g} / \mathrm{mL}$ for TRG and TAD, respectively. Using oneway analysis of variance (ANOVA), the optimized methods were compared and proved to be accurate for the simultaneous assay of TRG and TAD.

\section{Introduction}

Trelagliptin (TRG) (Figure 1) is a dipeptidyl peptidase-4 (DPP4) inhibitor for treating type 2 diabetes mellitus as a onceweekly monotherapy. Its mechanism of action includes inhibiting the DPP-4 enzyme that leads to increment of glucagon-like peptide-1 (GLP-1) and other hormone levels [1]. TRG administration once weekly showed a high efficacy and good safety profile $[2,3]$. TRG kinetic analysis revealed reversible and slow-binding inhibition of DPP-4, while X-ray diffraction data indicated a noncovalent interaction between DPP-4 and TRG $[4,5]$. DPP-4 inhibitors are weight neutral and well tolerated and provide better glycaemic control for a longer period compared to conventional therapies. Despite the fact that various drugs are available, glycaemic control remains suboptimal in approximately half of patients with type 2 diabetes mellitus, one of the major reasons for low medication adherence [6-8]. A novel DPP-4 inhibitor, TRG, was approved in Japan in March 2015 and is the first once-weekly oral antidiabetic agent in the world. Medication adherence for the treatment of diabetes was reviewed in the recent phases I, II, and III clinical studies. TRG has demonstrated superiority to placebo and noninferiority to alogliptin, indicating its efficacy and tolerance in Japanese patients. TRG is expected to improve adherence and prevent complications. Due to the convenient dosing regimen, it is expected to be widely used in the clinical setting [6-9].

Although some LC methods were reported for quantification of TRG [10-12], no methods were found in the literature dealing with the direct UV assay of TRG in its 


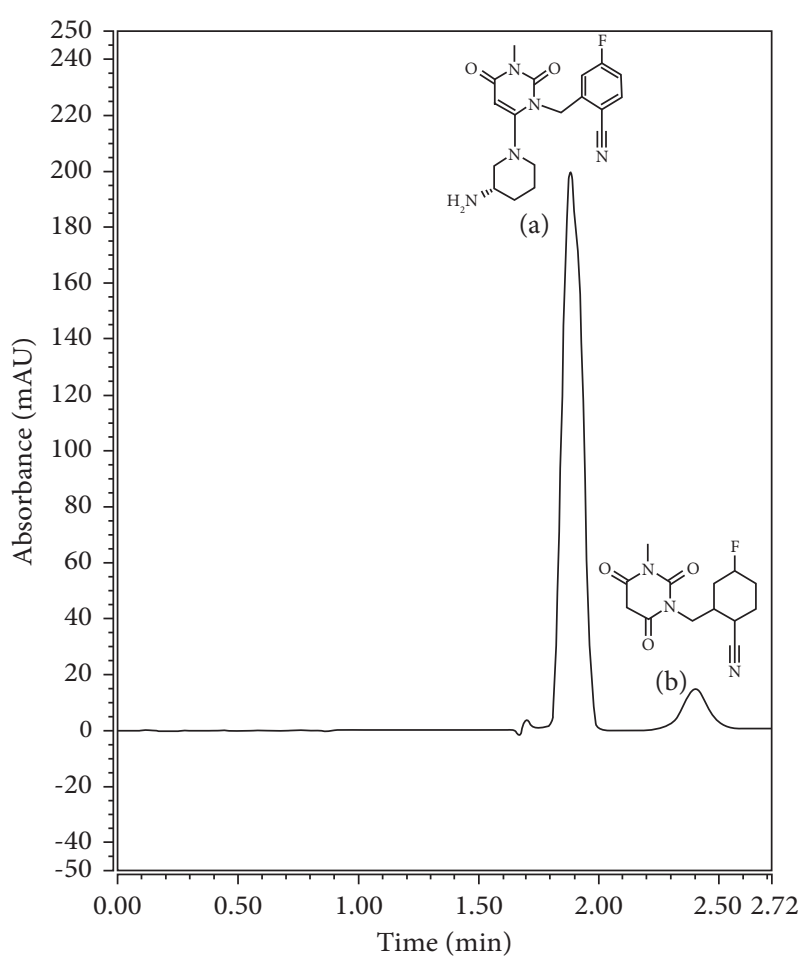

FIgURE 1: HPLC-UV chromatogram of laboratory-prepared mixture containing concentrations equivalent to $45 \mu \mathrm{g} / \mathrm{mL}$ and $9 \mu \mathrm{g} / \mathrm{mL}$ of TRG (a) and TAD (b), respectively.

pharmaceutical dosage form. In addition, no methods were used for the simultaneous assay of TRG and its acid degradation product (TAD) using UV spectrophotometric techniques. TAD (Figure 1) was found in the literature to be the main acid degradation product $[12,13]$, which is 2-[(3-methyl-2, 4, 6-oxo-tetrahydro-pyrimidin-1(2H) yl)methyl]-4-fluorobenzonitrile. Literature results were ascertained by separating TRG from its acid degradation product on the TLC that results in two separated spots before the complete degradation and showed only one spot after finalizing the stress conditions as reported [12, 13]. Moreover, in this presented work, HPLC-UV was used to confirm that we have one major degradation product where chromatographic separation of TRG from TAD was obtained with retention times for TRG and its acid degradation product equal to 1.86 and 2.43, respectively (Figure 1).

The present work is considered as the first spectrophotometric methods for the analysis of TRG in Zafatek ${ }^{\circledR}$ tablets and for simultaneous determination of TRG in the presence of TAD that are considered as simple and inexpensive techniques. This study presents different methods resolving the overlapped spectra of TRG and TAD by manipulating their zero-order, first-order, and ratio spectra using simultaneous equation, first-derivative, and mean-centering methods, respectively.

\section{Experimental}

2.1. Instruments. UV spectrophotometer (S/N C367961148, Japan, JASCO) was used.
2.2. Reagents, Reference Samples, and Stock and Working Solutions. TRG was certified to contain more than $99.0 \%$, and Zafatek tablets (each tablet contains $50 \mathrm{mg}$ of TRG) were provided by Takeda Pharmaceuticals Ltd. (Japan). Stock solutions $(1 \mathrm{mg} / \mathrm{mL})$ and their appropriate dilution to working solutions $(100 \mu \mathrm{g} / \mathrm{mL})$ of TRG were prepared separately in analytical grade methanol purchased from Sigma-Aldrich (Germany).

2.3. Sample Preparation. The coats of twenty Zafatek tablets were carefully removed; then, the tablets were powdered and mixed. An accurately weighed amount equivalent to $10 \mathrm{mg}$ of TRG was transferred to a $100 \mathrm{~mL}$ volumetric flask, completed to volume with methanol, sonicated to dissolve, and filtered. Two, three, and four milliliters of the previously prepared extract were added separately to a series of $10 \mathrm{~mL}$ volumetric flasks and completed to volume with methanol. The final TRG concentrations were equivalent to 20,30 , and $40 \mu \mathrm{g} / \mathrm{mL}$.

\subsection{Preparation of the Trelagliptin Acid Degradation Product} (TAD). Using TRG stock solution ( $1 \mathrm{mg} / \mathrm{mL})$, acidic hydrolysis of TRG was carried out in a Fischer brand disposable tube by mixing $2.5 \mathrm{~mL}$ of TRG stock solution with $2.5 \mathrm{~mL}$ of $1 \mathrm{~N} \mathrm{HCl}$ and was heated for 2 hours at $90^{\circ} \mathrm{C}$. At the specified time (after cooling the tube contents), a precalculated amount of $1 \mathrm{~N} \mathrm{NaOH}$ was added to neutralize the tube contents. Then, the tube contents were transferred into a $50 \mathrm{~mL}$ volumetric flask and completed to volume with methanol. Thus, the concentration of TAD was assumed to be $50 \mu \mathrm{g} / \mathrm{mL}$. Complete acidic hydrolysis of TRG was confirmed by injecting the sample into the HPLC-UV system that results in only one peak with a retention time of 2.43 (instead of TRG retention time that equals 1.86). Also, the sample was separated on TLC that results in only one spot that is corresponding to TAD. The sample was stored under $4^{\circ} \mathrm{C}$ until analysis.

\subsection{Procedure}

2.5.1. Preliminary Investigation. The zero-order absorption spectra of TRG $(30 \mu \mathrm{g} / \mathrm{mL})$ and TAD $(15 \mu \mathrm{g} / \mathrm{mL})$ were recorded separately against methanol as a blank. Overlay of both TRG and TAD spectra (Figure 2(a)) showed the maximum absorption $\left(\lambda_{\max }\right)$ at $274 \mathrm{~nm}$ and $260.4 \mathrm{~nm}$, respectively. Overlay of the first-order spectra of TRG $(30 \mu \mathrm{g} / \mathrm{mL})$ and TAD $(15 \mu \mathrm{g} / \mathrm{mL})$ showed the TAD zero crossing point at $260.4 \mathrm{~nm}$ and the TRG zero crossing point at $274.0 \mathrm{~nm}$, as shown in Figure 2(b).

2.5.2. Linearity. Aliquots of working solutions corresponding to $50-500 \mu \mathrm{g} / \mathrm{mL}$ and $25-250 \mu \mathrm{g} / \mathrm{mL}$ of TRG and TAD, respectively, were added separately into a series of $10 \mathrm{~mL}$ volumetric flasks and completed to volume with methanol. The corresponding absorbance was measured at $274.0 \mathrm{~nm}$ and $260.4 \mathrm{~nm}$ for TRG and TAD, respectively, using methanol as a blank. Calibration curves (absorbance against concentration) were constructed for both TRG and TAD. 


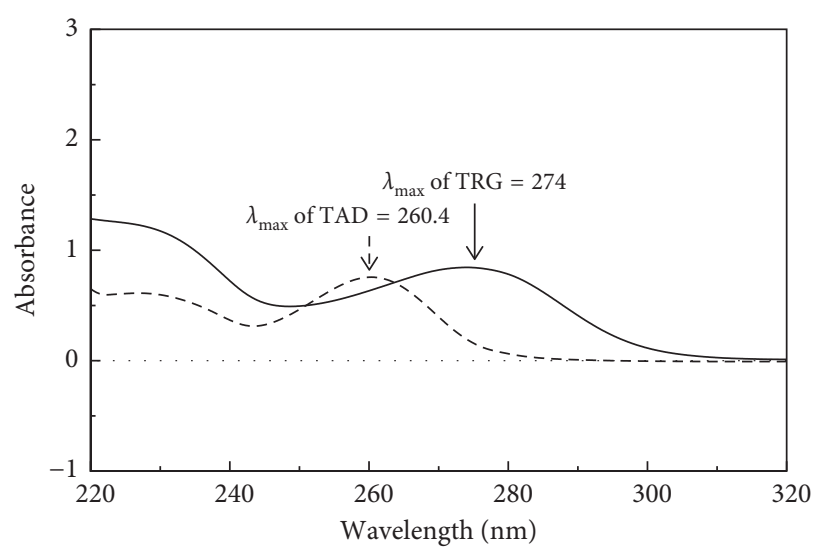

(a)

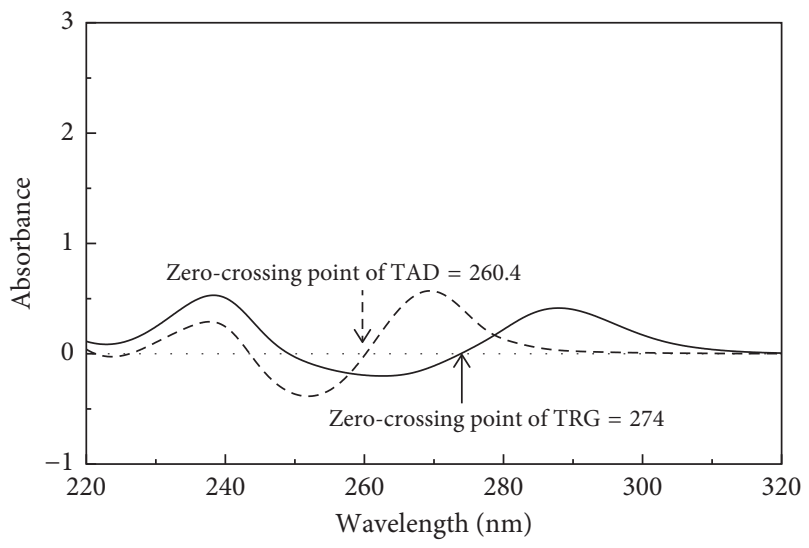

(b)

Figure 2: Overlay of the absorption spectra (a) and first-derivative spectra (b) of TRG $30 \mu \mathrm{g} / \mathrm{mL}$ (solid line) and TAD $15 \mu \mathrm{g} / \mathrm{mL}$ (dashed line), using methanol as a blank.

2.6. Simultaneous Equation Method. The simultaneous equation spectrophotometric method was successfully applied to TRG and TAD by manipulating their zero-order absorption spectra. TRG and TAD showed the maximum absorption $\left(\lambda_{\max }\right)$ at $274 \mathrm{~nm}\left(\lambda_{\max } 1\right)$ and $260.4 \mathrm{~nm}\left(\lambda_{\max } 2\right)$, respectively. Absorbance at $\lambda_{\max } 1$ and $\lambda_{\max } 2$ was plotted against the corresponding concentrations of TRG and TAD, respectively, and calibration curves were constructed. Mixtures of TRG and TAD with different lambdas and concentrations of TRG and TAD ( $\mathrm{C}_{\mathrm{TRG}}$ and $\left.\mathrm{C}_{\mathrm{TAD}}\right)$ can be calculated by a simultaneous equation. Through absorbance of the sample at $\lambda 1$ and $\lambda 2$ ( $A 1$ and $A 2)$, absorptivities of TRG at $\lambda_{\max } 1$ and $\lambda_{\max } 2$ ( $a_{\mathrm{TRG}} 1$ and $\left.a_{\mathrm{TRG}} 2\right)$ and absorptivities of TAD at $\lambda_{\max } 1$ and $\lambda_{\max } 2\left(a_{\mathrm{TAD}} 1\right.$ and $\left.a_{\mathrm{TAD}} 2\right)$ are as follows:

$$
\begin{aligned}
C_{\mathrm{TRG}} & =\frac{\left[\left(A 2 * a_{\mathrm{TAD}} 1\right)-\left(A 1 * a_{\mathrm{TAD}} 2\right)\right]}{\left[\left(a_{\mathrm{TRG}} 2 * a_{\mathrm{TAD}} 1\right)-\left(a_{\mathrm{TRG}} 1 * a_{\mathrm{TAD}} 2\right)\right]}, \\
C_{\mathrm{TAD}} & =\frac{\left[\left(A 1 * a_{\mathrm{TRG}} 2\right)-\left(A 2 * a_{\mathrm{TRG}} 1\right)\right]}{\left[\left(a_{\mathrm{TRG}} 2 * a_{\mathrm{TAD}} 1\right)-\left(a_{\mathrm{TRG}} 1 * a_{\mathrm{TAD}} 2\right)\right]} .
\end{aligned}
$$

The total absorbance is the sum of TRG and TAD absorbance, as their $\lambda_{\max }$ are relatively dissimilar and they do not interact chemically.

2.7. First-Derivative Method. The first-derivative spectrophotometric method was successfully applied to TRG and TAD by manipulating their first-order spectra. The amplitudes of the first-order spectra were measured for TRG and TAD at $260.4 \mathrm{~nm}$ and $274 \mathrm{~nm}$, respectively. Then, the amplitudes were plotted against corresponding concentrations of TRG and TAD to construct calibration curves.

2.8. Mean-Centering Method. The scanned zero-order spectra of TRG and TAD were separately divided by $25 \mu \mathrm{g} / \mathrm{mL}$ of $\mathrm{TAD}$ and $50 \mu \mathrm{g} / \mathrm{mL}$ of $\mathrm{TRG}$, respectively. Using the Minitab v.14 program, the obtained ratio spectra were mean centered and then, the mean-centered values of
TRG and TAD were measured at $287.6 \mathrm{~nm}$ and $257.2 \mathrm{~nm}$, respectively. Calibration curves were constructed by plotting the mean-centered values against corresponding concentrations.

2.8.1. Accuracy and Precision. Three different ratios of the drug and its degradation product (TAD equals to $10 \%, 15 \%$, and $20 \%$ of TRG) as 3 laboratory-prepared mixtures were applied using concentrations corresponding to 35,40 , and $45 \mu \mathrm{g} / \mathrm{mL}$ and $3.5,6$, and $9 \mu \mathrm{g} / \mathrm{mL}$ of TRG and TAD, respectively. The zero-order absorption spectra of the mixtures were recorded using methanol as a blank. Finally, the obtained spectra were manipulated by different methods to calculate the corresponding concentration of each drug. Furthermore, they were analyzed using the proposed methods three times within the same day $(n=3)$ and on three successive days $(n=3)$. The percent recoveries $(\% R)$ and the percent relative standard deviation (\% RSD) were calculated for each method.

2.8.2. Assay of Zafatek Tablets. The absorbance spectrum of the tablet extract prepared under Sample Preparation was recorded. Then, the percent recoveries and standard deviation were calculated.

\section{Results and Discussion}

Calibration curves for the simultaneous equation method were constructed by plotting absorbance of TRG and TAD (Figures 3(a) and 3(b)) against the corresponding concentrations. A simultaneous equation at the specified lambdas (274.0 $\mathrm{nm}$ and $260.4 \mathrm{~nm}$ ) was used to get the corresponding concentration of TRG and TAD in their mixtures. Then, the percent recoveries of both TRG and TAD were calculated for the three laboratory-prepared mixtures (Table 1).

Calibration curves for the first-derivative method were constructed by plotting amplitudes of TRG and TAD (Figures 4(a) and 4(b)) against the corresponding concentrations. The concentrations of TRG and TAD were 


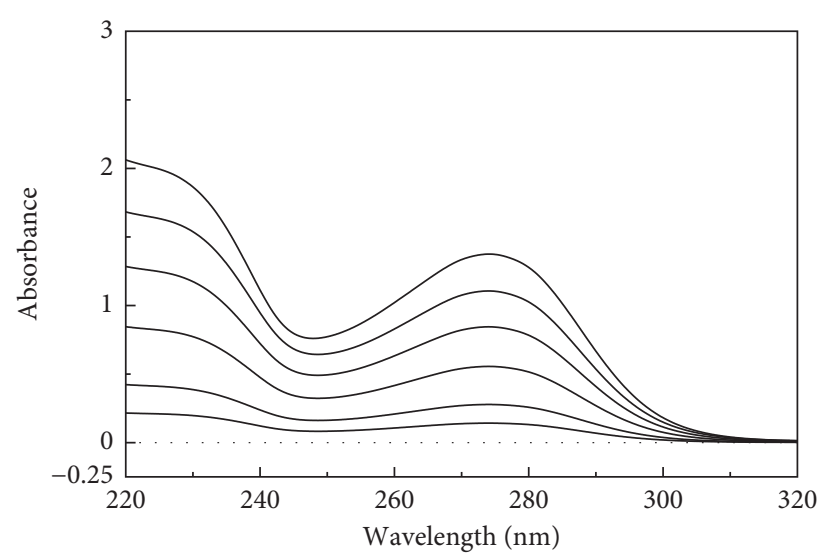

(a)

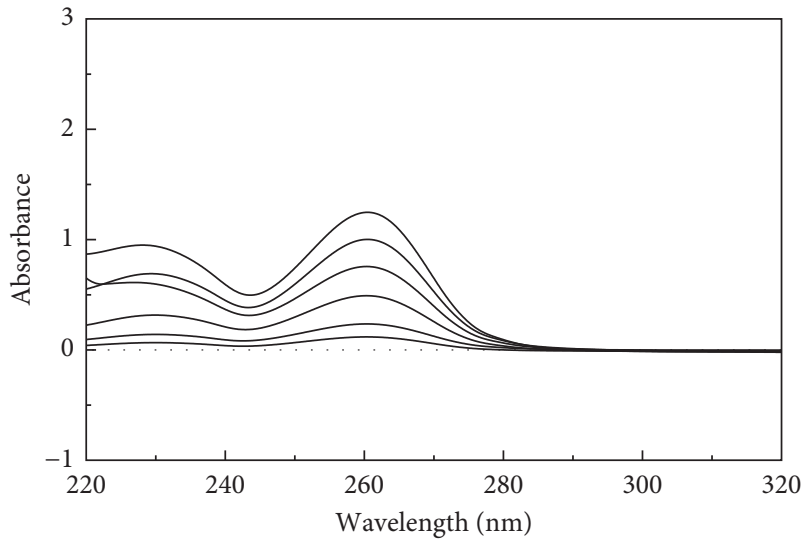

(b)

FiguRE 3: Overlay of the zero-order absorption spectra of TRG $(5,10,20,30,40$, and $50 \mu \mathrm{g} / \mathrm{mL})(\mathrm{a})$ and TAD $(2.5,5,10,15,20$, and $25 \mu \mathrm{g} / \mathrm{mL})$ (b), using methanol as a blank.

TABLE 1: Results obtained by the proposed simultaneous equation spectrophotometric method for determination of TRG and TAD.

\begin{tabular}{|c|c|c|c|c|}
\hline Item & TRG at $274 \mathrm{~nm}$ & TRG at $260.4 \mathrm{~nm}$ & $\mathrm{TAD}$ at $274 \mathrm{~nm}$ & TAD at $260.4 \mathrm{~nm}$ \\
\hline Range of linearity $(\mu \mathrm{g} / \mathrm{mL})$ & $5-50$ & $5-50$ & $2.5-25$ & $2.5-25$ \\
\hline Regression equation & $\begin{aligned} A= & 0.0276 \mathrm{C} \cdot \mu \mathrm{g} / \mathrm{mL} \\
& +0.0056\end{aligned}$ & $\begin{aligned} A= & 0.0208 \mathrm{C} \cdot \mu \mathrm{g} / \mathrm{mL} \\
& +0.0063\end{aligned}$ & $A=0.0129 \mathrm{C} \cdot \mu \mathrm{g} / \mathrm{mL}-0.0050$ & $A=0.0505 \mathrm{C} \cdot \mu \mathrm{g} / \mathrm{mL}-0.0117$ \\
\hline Regression coefficient $(r)$ & 0.9999 & 0.9997 & 0.9990 & 0.9999 \\
\hline $\mathrm{LOD}(\mu \mathrm{g} / \mathrm{mL})$ & $1.01 \mu \mathrm{g} / \mathrm{mL}$ & 1.45 & 0.76 & 0.42 \\
\hline LOQ $(\mu \mathrm{g} / \mathrm{mL})$ & $3.05 \mu \mathrm{g} / \mathrm{mL}$ & 4.41 & 2.32 & 1.27 \\
\hline${ }^{*} S_{b}$ & $2.16 \times 10^{-4}$ & $2.35 \times 10^{-4}$ & $1.54 \times 10^{-4}$ & $3.28 \times 10^{-4}$ \\
\hline${ }^{*} S_{a}$ & 0.008 & 0.009 & 0.003 & 0.006 \\
\hline Confidence limit of the slope & $0.0276 \times 5.95 \times 10^{-6}$ & $0.0208 \times 4.89 \times 10^{-6}$ & $0.0129 \times 1.99 \times 10^{-6}$ & $0.0505 \times 1.66 \times 10^{-5}$ \\
\hline $\begin{array}{l}\text { Confidence limit of the } \\
\text { intercept }\end{array}$ & $0.0056 \times 4.50 \times 10^{-5}$ & $0.0063 \times 5.46 \times 10^{-5}$ & $-0.0050 \times 1.42 \times 10^{-5}$ & $-0.0117 \times 7.11 \times 10^{-5}$ \\
\hline $\begin{array}{l}\text { Standard error of the } \\
\text { estimation }\end{array}$ & 0.009 & 0.008 & 0.003 & 0.006 \\
\hline $\begin{array}{l}\text { Accuracy } \\
\text { Laboratory prepared } \\
(\text { mean } \pm S D)\end{array}$ & \multicolumn{2}{|c|}{$100.66 \pm 0.10$} & \multicolumn{2}{|c|}{$100.96 \pm 0.86$} \\
\hline $\begin{array}{l}\text { Standard addition (mean } \pm \\
\text { SD) }\end{array}$ & \multicolumn{2}{|c|}{$98.55 \pm 1.70$} & \multicolumn{2}{|c|}{-} \\
\hline $\begin{array}{l}\text { Precision } \\
\text { Intraday \% RSD }\end{array}$ & \multicolumn{2}{|c|}{$0.04-0.53-0.56$} & \multicolumn{2}{|c|}{$0.05-0.54-0.55$} \\
\hline Interday \% RSD & \multicolumn{2}{|c|}{$0.40-0.54-0.92$} & \multicolumn{2}{|c|}{$0.45-0.52-0.92$} \\
\hline $\begin{array}{l}\text { Drug in dosage form (mean } \pm \\
\text { SD) }\end{array}$ & \multicolumn{2}{|c|}{$100.98 \pm 0.39$} & \multicolumn{2}{|c|}{-} \\
\hline
\end{tabular}

*Standard deviations of the slope $S_{b} \&$ intercept $S_{a}$.

calculated by applying the corresponding regression equations, as shown in Table 2.

For the mean-centering method, the absorption spectra of TRG and TAD were separately divided by the zero-order spectra of $50 \mu \mathrm{g} / \mathrm{mL}$ TRG and $25 \mu \mathrm{g} / \mathrm{mL}$ TAD to get the ratio spectra that were mean centered using the Minitab program. Influences of different variables were studied, including divisor concentration and smoothing factor. Different concentrations were tried as divisors $(30-60 \mu \mathrm{g} / \mathrm{mL}$ of TRG and $15-35 \mu \mathrm{g} / \mathrm{mL}$ of TAD). The selected divisors $(50 \mu \mathrm{g} / \mathrm{mL}$ TRG and $25 \mu \mathrm{g} / \mathrm{mL}$ TAD) showed minimum noise, maximum sensitivity, and smoother ratio spectra, as shown in Figures 5(a) and 5(b). Mean centering was applicable, as TRG and TAD are noninteractive to each other, and each of them obeys Beer's law according to the following equation $\left(V_{a}=\mathrm{A}_{\mathrm{TRG}}\right.$ $\mathrm{C}_{\mathrm{TRG}}+\mathrm{A}_{\mathrm{TAD}} \mathrm{C}_{\mathrm{TAD}}$ ), where $V_{a}$ is the vector of absorbance, $\mathrm{A}_{\mathrm{TRG}}-\mathrm{A}_{\mathrm{TAD}}$ are the molar absorptivities, and $\mathrm{C}_{\mathrm{TRG}}-\mathrm{C}_{\mathrm{TAD}}$ are the concentrations of TRG and TAD, respectively. After division over $\mathrm{A}_{\mathrm{TAD}}$, the resultant ratio spectra 


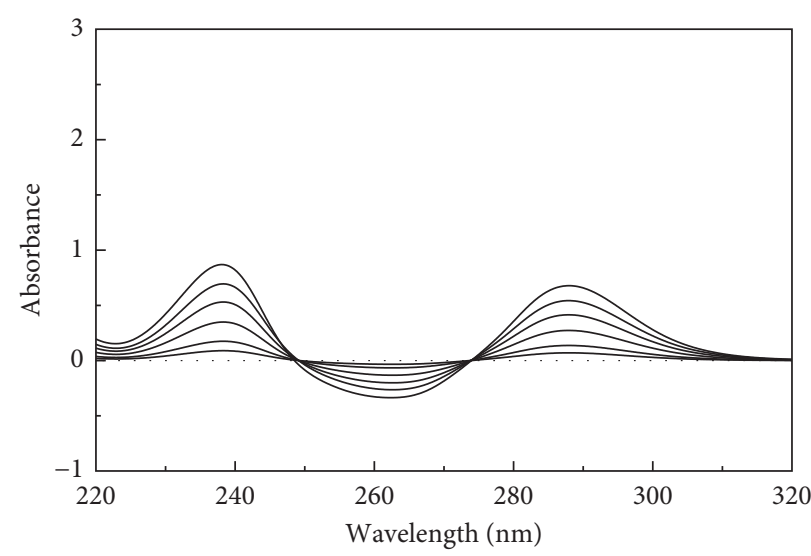

(a)

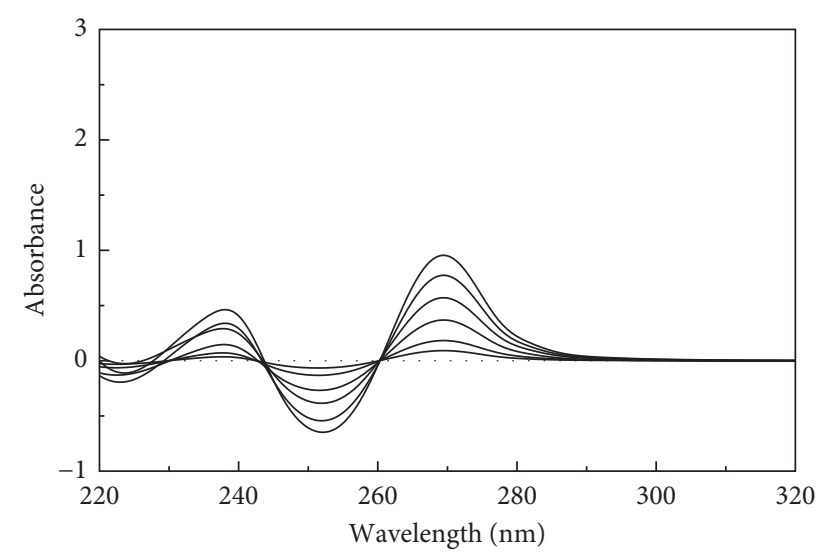

(b)

FIGURE 4: Overlay of the first-order spectra of TRG $(5,10,20,30,40$, and $50 \mu \mathrm{g} / \mathrm{mL})(\mathrm{a})$ and TAD $(2.5,5,10,15,20$, and $25 \mu \mathrm{g} / \mathrm{mL})(\mathrm{b})$, using methanol as a blank.

TABLE 2: Results obtained by the proposed first-derivative spectrophotometric method for determination of TRG and TAD.

\begin{tabular}{|c|c|c|}
\hline Item & TRG at $260.4 \mathrm{~nm}$ & TAD at $274 \mathrm{~nm}$ \\
\hline Range of linearity $(\mu \mathrm{g} / \mathrm{mL})$ & $5-50$ & $2.5-25$ \\
\hline Regression equation & $A=0.0067 \mathrm{C} \cdot \mu \mathrm{g} / \mathrm{mL}-0.0008$ & $A=0.0288 \mathrm{C} \cdot \mu \mathrm{g} / \mathrm{mL}-0.0094$ \\
\hline Regression coefficient $(r)$ & 0.9998 & 0.9997 \\
\hline $\mathrm{LOD}(\mu \mathrm{g} / \mathrm{mL})$ & 1.21 & 0.77 \\
\hline LOQ $(\mu \mathrm{g} / \mathrm{mL})$ & 3.67 & 2.34 \\
\hline${ }^{*} S_{b}$ & $6.31 \times 10^{-5}$ & $5.41 \times 10^{-4}$ \\
\hline${ }^{*} S_{a}$ & 0.002 & 0.006 \\
\hline Confidence limit of the slope & $0.0067 \pm 4.23 \times 10^{-7}$ & $0.0288 \pm 9.93 \times 10^{-6}$ \\
\hline Confidence limit of the intercept & $-0.0008 \pm 1.87 \times 10^{-6}$ & $-0.0094 \pm 6.05 \times 10^{-5}$ \\
\hline Standard error of the estimation & 0.002 & 0.006 \\
\hline $\begin{array}{l}\text { Accuracy } \\
\text { Laboratory prepared }(\text { mean } \pm S D)\end{array}$ & $99.43 \pm 0.78$ & $99.31 \pm 0.45$ \\
\hline Standard addition $($ mean $\pm S D)$ & $99.51 \pm 1.36$ & \\
\hline $\begin{array}{l}\text { Precision } \\
\text { Intraday \% RSD }\end{array}$ & $0.45-0.53-0.71$ & $0.43-0.51-0.64$ \\
\hline Interday \% RSD & $0.28-0.41-0.51$ & $0.27-0.39-0.46$ \\
\hline Drug in dosage form $($ mean $\pm \mathrm{SD})$ & $99.37 \pm 0.89$ & \\
\hline
\end{tabular}

${ }^{*}$ Standard deviations of the slope $S_{b} \&$ intercept $S_{a}$.

were mean centered; $\mathrm{C}_{\mathrm{TAD}}$ will be zero value enabling the determination of $\mathrm{C}_{\text {TRG }}$ without interference from $\mathrm{TAD}$ and the same concept regarding $\mathrm{A}_{\mathrm{TRG}}$, as shown in Table 3.

\subsection{Validation according to ICH Guidelines}

3.1.1. Linearity. The linearity of the calibration curves was confirmed by LOD-LOQ parameters, STEYX, $S_{b}$, and $S_{a}$ as shown in Tables $1-3$, where LOD is the limit of detection, LOQ is the limit of quantification, STEYX is the standard error of estimation, $S_{b}$ is the standard deviation of the slope, and $S_{a}$ is the standard deviation of the intercept. Also, the methods were adopted successfully for the assay of TRG and
TAD in their mixtures. Acceptable results of the regression parameters were achieved as shown in Tables 1-3 [14].

3.1.2. Accuracy and Precision. Accuracy was checked by calculating the percent recoveries of TRG and TAD in their laboratory-prepared mixtures, while precision values were checked using their intraday and interday records, $n=3$, as shown in Tables 1-3.

3.1.3. Specificity and Application on the Pharmaceutical Dosage Form. TRG was determined in its laboratoryprepared mixtures with TAD and in Zafatek tablets without interference from the excipients of the 


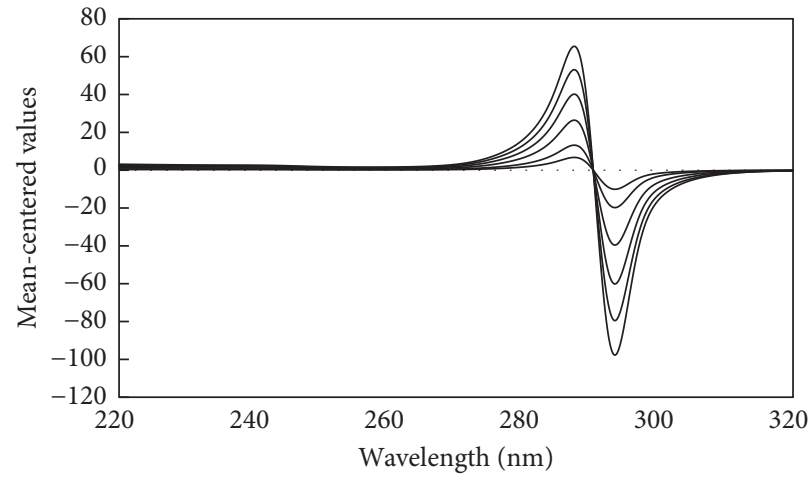

(a)

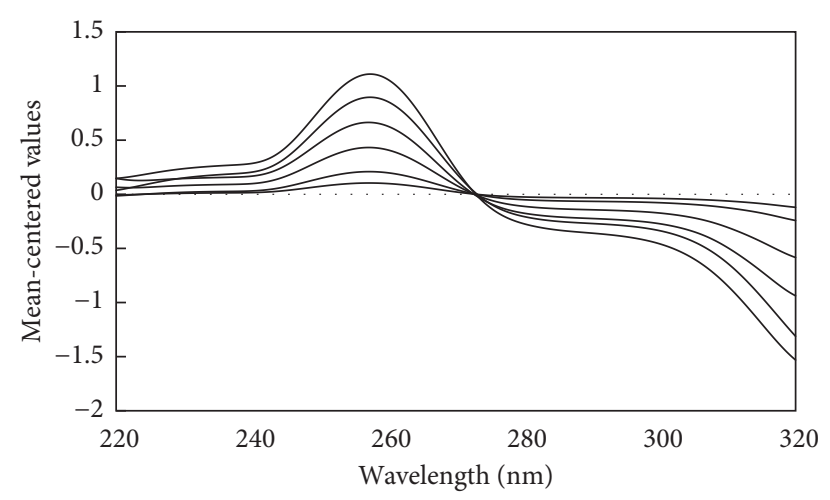

(b)

FIGURE 5: The mean-centered values of the ratio spectra representing 5-50 $\mu \mathrm{g} / \mathrm{mL}$ TRG divided by $25 \mu \mathrm{g} / \mathrm{mL}$ of TAD (a) and the ratio spectra of $5-25 \mu \mathrm{g} / \mathrm{mL}$ TAD divided by $50 \mu \mathrm{g} / \mathrm{mL}$ of TRG (b), using methanol as a blank.

TABLE 3: Results obtained by the proposed mean-centering spectrophotometric method for determination of TRG and TAD.

\begin{tabular}{|c|c|c|}
\hline Item & TRG at $287.6 \mathrm{~nm}$ & $\mathrm{TAD}$ at $257.2 \mathrm{~nm}$ \\
\hline Range of linearity $(\mu \mathrm{g} / \mathrm{mL})$ & $5-50$ & $2.5-25$ \\
\hline Regression equation & $A=1.3134 \mathrm{C} \cdot \mu \mathrm{g} / \mathrm{mL}+0.2489$ & $A=0.0451 \mathrm{C} \cdot \mu \mathrm{g} / \mathrm{mL}-0.0135$ \\
\hline Regression coefficient $(r)$ & 0.9999 & 0.9999 \\
\hline LOD $(\mu \mathrm{g} / \mathrm{mL})$ & 0.98 & 0.42 \\
\hline LOQ $(\mu \mathrm{g} / \mathrm{mL})$ & 2.98 & 1.29 \\
\hline${ }^{*} S_{b}$ & $1.00 \times 10^{-2}$ & $2.97 \times 10^{-4}$ \\
\hline${ }^{*} S_{a}$ & 0.373 & 0.006 \\
\hline Confidence limit of the slope & $1.3134 \pm 1.32 \times 10^{-2}$ & $0.0451 \pm 1.34 \times 10^{-5}$ \\
\hline Confidence limit of the intercept & $0.2489 \pm 9.29 \times 10^{-}$ & $-0.0135 \pm 7.45 \times 10^{-5}$ \\
\hline Standard error of the estimation & 0.392 & 0.006 \\
\hline $\begin{array}{l}\text { Accuracy } \\
\text { Laboratory prepared }(\text { mean } \pm S D)\end{array}$ & $99.99 \pm 0.14$ & $101.24 \pm 0.08$ \\
\hline Standard deviation $($ mean $\pm \mathrm{SD})$ & $98.90 \pm 1.75$ & \\
\hline $\begin{array}{l}\text { Precision } \\
\text { Intraday \% RSD }\end{array}$ & $0.37-0.43-0.47$ & $0.34-0.43-0.45$ \\
\hline Interday \% RSD & $0.16-0.27-0.76$ & $0.16-0.25-0.73$ \\
\hline Drug in dosage form (mean $\pm \mathrm{SD})$ & $98.92 \pm 1.85$ & \\
\hline
\end{tabular}

*Standard deviations of the slope $S_{b} \&$ intercept $S_{a}$.

TABLE 4: Statistical comparison between the proposed spectrophotometric methods.

\begin{tabular}{lcccccc}
\hline \multirow{2}{*}{ Statistical term } & \multicolumn{2}{c}{ TRG } & & \multicolumn{2}{c}{ TAD } \\
& Simultaneous equation & First derivative & Mean centering & Simultaneous equation & First derivative & Mean centering \\
\hline Mean & 100.66 & 99.43 & 99.99 & 100.96 & 99.31 & 101.24 \\
SD \pm & 0.10 & 0.78 & 0.14 & 0.86 & 0.45 & 0.08 \\
$\%$ RSD & 0.10 & 0.78 & 0.14 & 0.85 & 0.45 & 3 \\
$n$ & 3 & 3 & 3 & 0.08 & 3 \\
$V$ & 0.01 & 0.61 & 0.02 & 0.74 & 0.20 & 0.01 \\
\hline
\end{tabular}

Note. The values in parentheses are the theoretical values at $p=0.05$. ANOVA results confirmed that there is no significant difference between groups of TRG $(F=5.350$ and $p=0.046)$ and $\operatorname{TAD}(F=10.320$ and $p=0.011)$ at $p=0.05$.

pharmaceutical dosage form. The mean of the percent recoveries and standard deviation were calculated, as shown in Tables 1-3.
3.2. Statistical Comparison. ANOVA comparison of the proposed methods at $p=0.05$ showed no significant difference, as shown in Table 4. 


\section{Conclusion}

The optimized analytical methods were confirmed to be precise and accurate for determination of TRG and TAD based on the simple economic assay. The methods were applied successfully on the pharmaceutical dosage form, with acceptable validation results. Simultaneous determination for laboratory-prepared mixtures of TRG and TAD was achieved through manipulating their zero-order, first-order, and ratio spectra. The developed methods should be of interest to the analysts in the area of drug control and can be used by QC laboratories.

\section{Conflicts of Interest}

The authors declare that they have no conflicts of interest.

\section{References}

[1] R. N. Kushwaha, W. Haq, and S. B. Katti, "Sixteen-years of clinically relevant dipeptidyl peptidase-IV (DPP-IV) inhibitors for treatment of type-2 diabetes: a perspective," Current Medicinal Chemistry, vol. 21, no. 35, pp. 4013-4045, 2014.

[2] D. Stoimenis, T. Karagiannis, A. Katsoula et al., "Once-weekly dipeptidyl peptidase- 4 inhibitors for type 2 diabetes: a systematic review and meta-analysis," Expert Opinion on Pharmacotherapy, vol. 18, no. 9, pp. 843-851, 2017.

[3] N. Harada and N. Inagaki, "Once-weekly DPP-4 inhibitor," Nihon Rinsho. Japanese Journal of Clinical Medicine, vol. 73, no. 12, pp. 2096-2102, 2015.

[4] K. Kaku, "Safety evaluation of trelagliptin in the treatment of Japanese type 2 diabetes mellitus patients," Expert Opinion on Drug Safety, vol. 16, no. 11, pp. 1313-1322, 2017.

[5] K. McKeage, "Trelagliptin: first global approval," Drugs, vol. 75, no. 10, pp. 1161-1164, 2015.

[6] K. Kaku, "First novel once-weekly DPP-4 inhibitor, trelagliptin, for the treatment of type 2 diabetes mellitus," Expert Opinion on Pharmacotherapy, vol. 16, no. 16, pp. 2539-2547, 2015.

[7] J. Yang, S. P. Zhan, and H. Y. Zhang, "Clinical application review of the novel once-weekly DPP-4 inhibitor trelagliptin in the treatment of type 2 diabetes," Chinese Journal of New Drugs, vol. 26, no. 2, pp. 145-150, 2017.

[8] M. Murakami, N. Hirahara, H. Morita, and S. Sasaki, "Efficacy and safety of trelagliptin, a once-weekly dipeptidyl peptidase- 4 (DPP-4) inhibitor: a non-inferiority study in switching from daily DPP-4 inhibitor for the treatment of type 2 diabetes patients," Journal of the Japan Diabetes Society, vol. 60, no. 3 , pp. 222-228, 2017.

[9] C. E. Grimshaw, A. Jennings, R. Kamran et al., "Trelagliptin (syr-472, Zafatek), novel once-weekly treatment for type 2 diabetes, inhibits dipeptidyl peptidase-4 (dpp-4) via a noncovalent mechanism," PLoS One, vol. 11, no. 6, Article ID 0157509, 2016

[10] X. Hu, T. Lan, Z. Chen et al., "A rapid and sensitive UHPLCMS/MS assay for the determination of trelagliptin in rat plasma and its application to a pharmacokinetic study," Journal of Chromatography B: Analytical Technologies in the Biomedical and Life Sciences, vol. 1033-1034, pp. 166-171, 2016.

[11] Q. Wang, X. Chen, C. Zhang et al., "Determination of the enantiomeric purity of trelagliptin by pre-column derivatization and liquid chromatography on a chiral stationary phase," Chromatographia, vol. 78, no. 21-22, pp. 1395-1400, 2015.

[12] H. Zhang, L. Sun, L. Zou et al., "Identification, characterization and HPLC quantification of process-related impurities in trelagliptin succinate bulk drug: six identified as new compounds," Journal of Pharmaceutical and Biomedical Analysis, vol. 128, pp. 18-27, 2016.

[13] S. Deng, Z. Li, J. Jiang et al., "Determination of related substances in trelagliptin succinate by RP-HPLC and identification of impurities from acid degradation by LC-MS/MS," Chinese Journal of New Drugs, vol. 25, no. 2, pp. 226-231, 2016.

[14] International Conference on Harmonization (ICH), Q2B: Validation of Analytical Procedures: Methodology, 62, US FDA, Federal Register, Washington, DC, USA, 1997. 

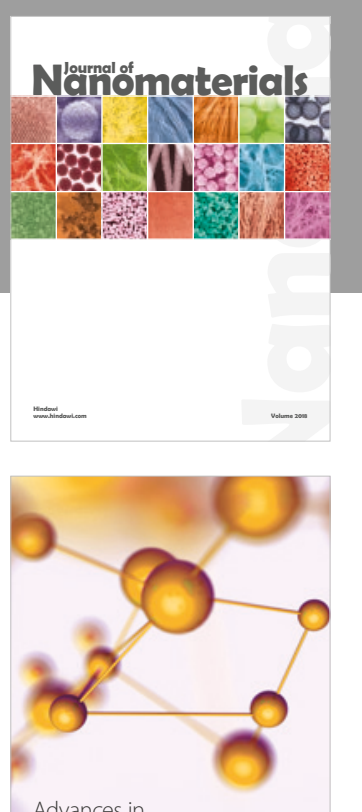

Physical Chemistry
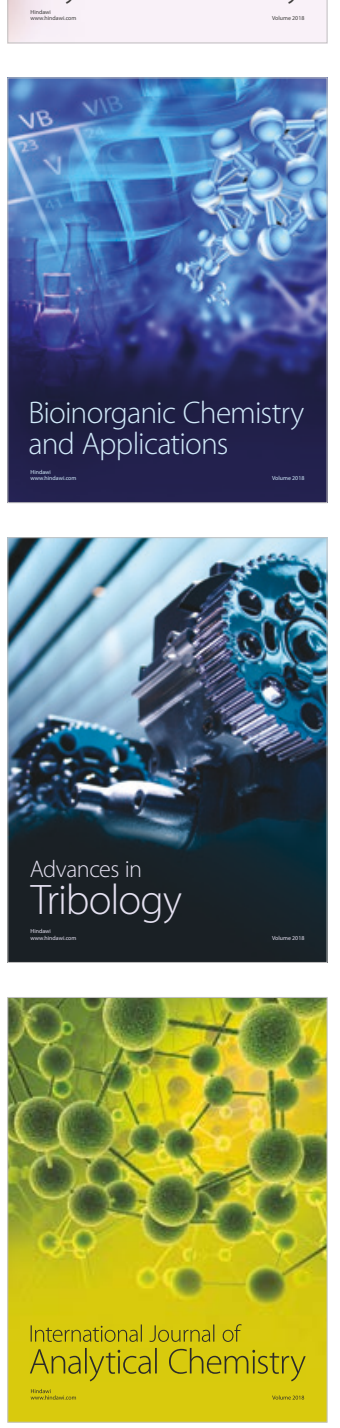

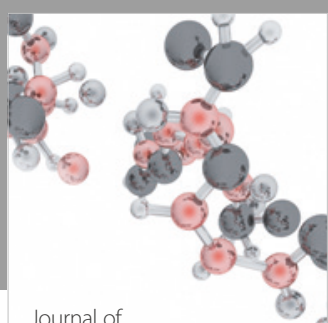

Analytical Methods

in Chemistry

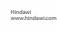

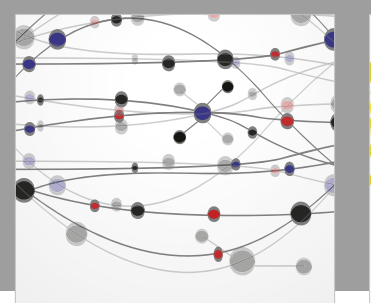

The Scientific World Journal

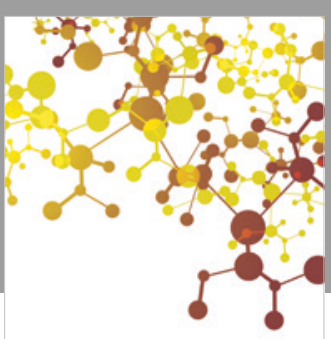

Journal of

Applied Chemistry
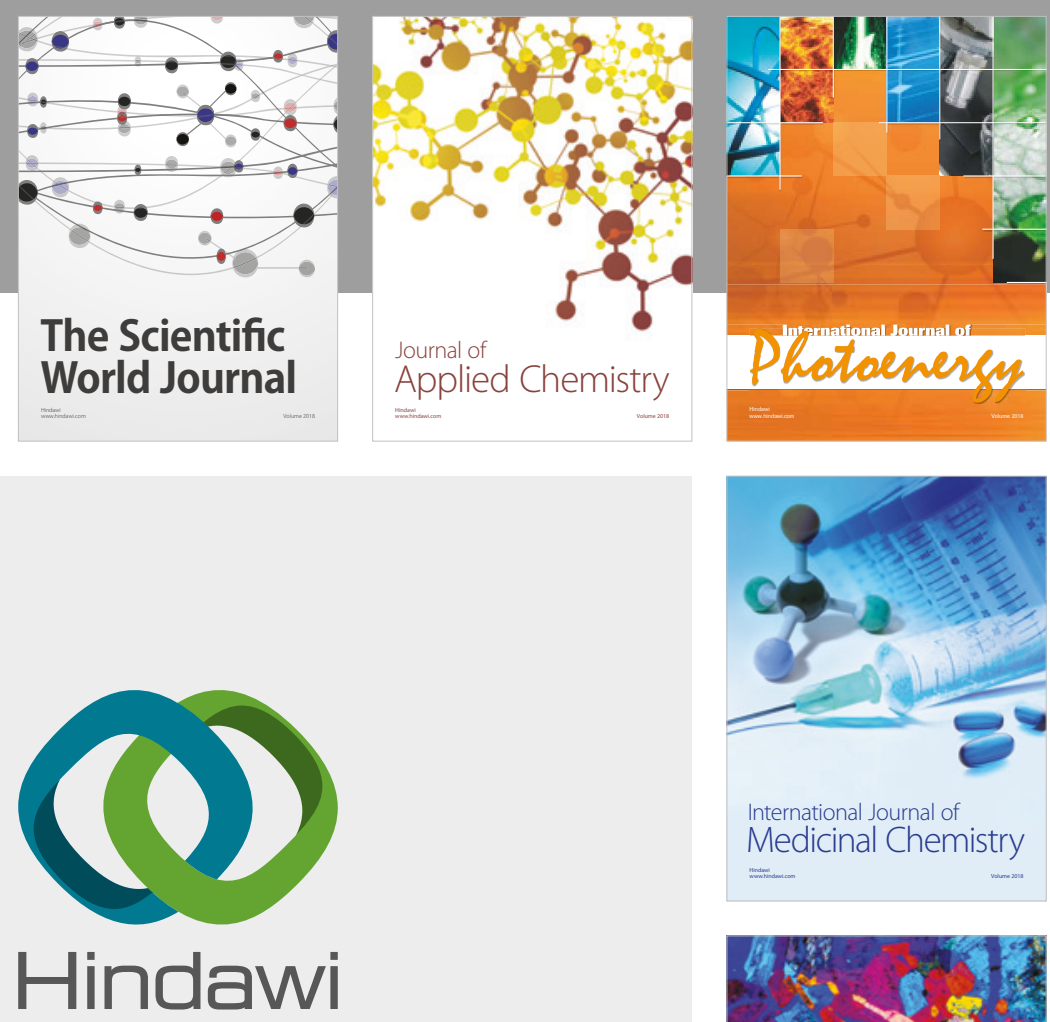

Submit your manuscripts at

www.hindawi.com
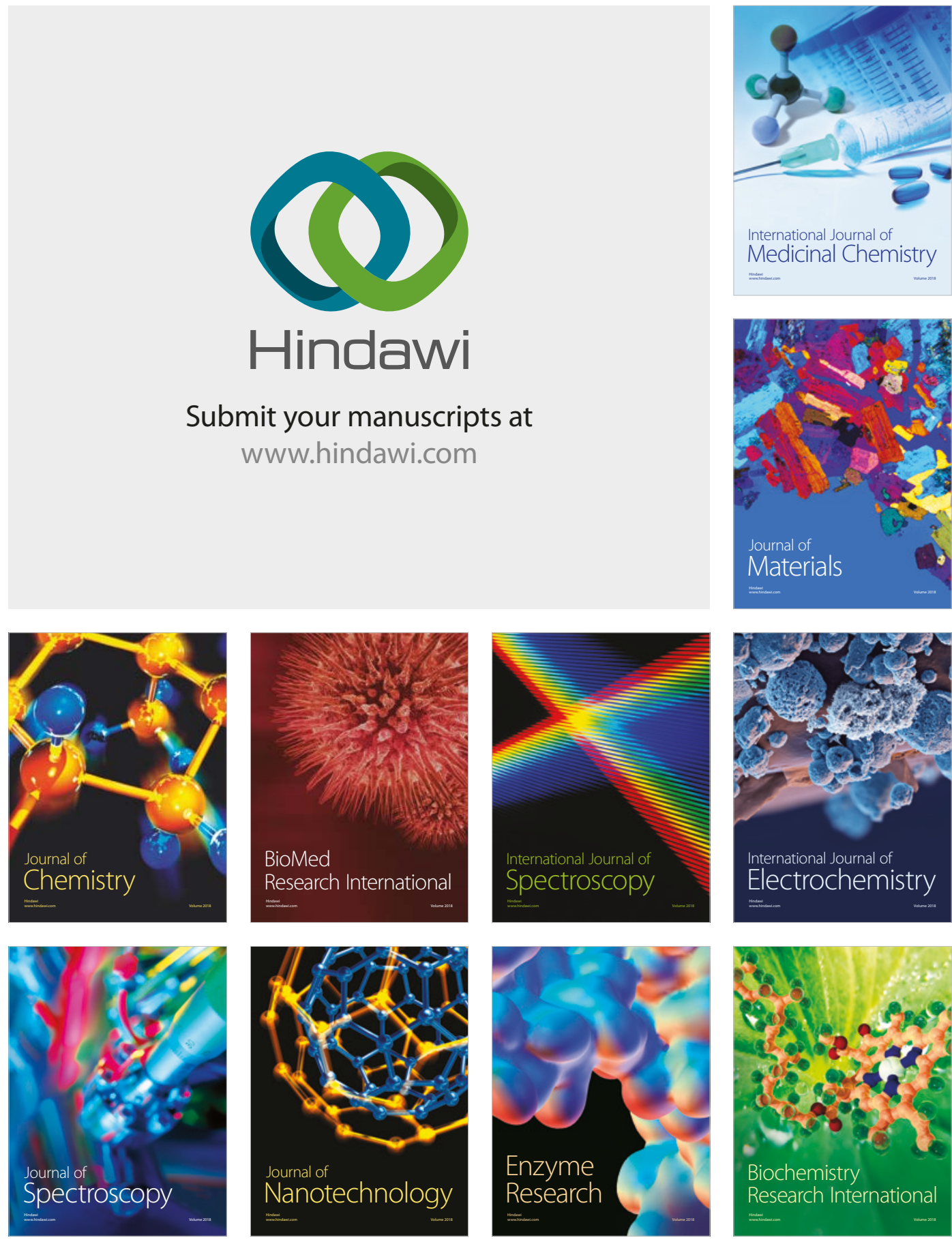
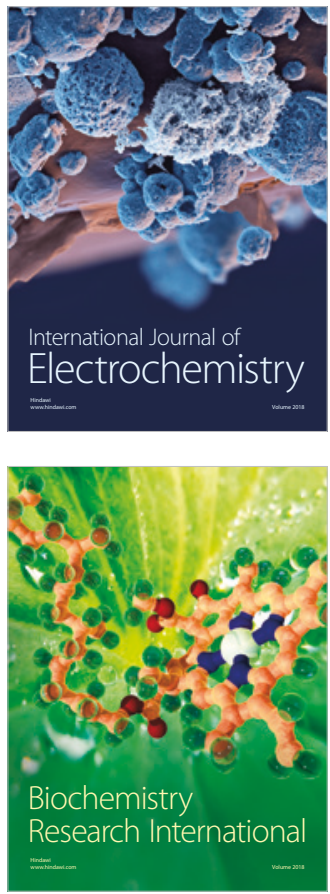